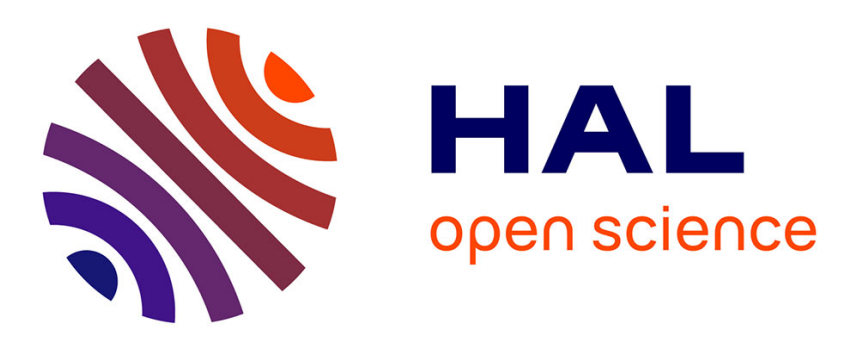

\title{
Enhanced Electrochemiluminescence of Porphyrin-Based Metal-Organic Frameworks Controlled via Coordination Modulation
}

\author{
Wen-Rong Cai, Hai-Bo Zeng, Huai-Guo Xue, Robert Marks, Serge Cosnier, \\ Xue-Ji Zhang, Dan Shan
}

\section{To cite this version:}

Wen-Rong Cai, Hai-Bo Zeng, Huai-Guo Xue, Robert Marks, Serge Cosnier, et al.. Enhanced Electrochemiluminescence of Porphyrin-Based Metal-Organic Frameworks Controlled via Coordination Modulation. Analytical Chemistry, 2020, 92 (2), pp.1916-1924. 10.1021/acs.analchem.9b04104 . hal03039136

\section{HAL Id: hal-03039136 \\ https://hal.science/hal-03039136}

Submitted on 3 Dec 2020

HAL is a multi-disciplinary open access archive for the deposit and dissemination of scientific research documents, whether they are published or not. The documents may come from teaching and research institutions in France or abroad, or from public or private research centers.
L'archive ouverte pluridisciplinaire $\mathbf{H A L}$, est destinée au dépôt et à la diffusion de documents scientifiques de niveau recherche, publiés ou non, émanant des établissements d'enseignement et de recherche français ou étrangers, des laboratoires publics ou privés. 
Manuscript ID: ac-2019-04104n.R2

Enhanced Electrochemiluminescence of Porphyrin-based Metal-Organic Frameworks Controlled via Coordination Modulation

Wen-Rong Cai ${ }^{\dagger}$, Hai-Bo Zeng ${ }^{\dagger}$, Huai-Guo Xue ${ }^{\ddagger}$, Robert S. Marks ${ }^{\S}$, Serge

Cosnier\&, Xue-Ji Zhang $^{\dagger}$, Dan Shan ${ }^{\dagger} *$

${ }^{\dagger}$ MIIT Key Laboratory of Advanced Display Materials and Devices, School of Environmental and Biological Engineering, Nanjing University of Science and Technology, Nanjing 210094, China.

${ }^{*}$ School of Chemistry and Chemical Engineering, Yangzhou University, Yangzhou 225002, China.

${ }^{\S}$ Department of Biotechnology Engineering, Ben-Gurion University of the Negev, Beer-Sheva, Israel.

\& University of Grenoble Alpes-CNRS, DCM UMR 5250, F-38000 Grenoble, France

${ }^{*}$ Corresponding author:

Email: danshan@njust.edu.cn (D. Shan)

Fax: 0086-25-84303107 


\section{ABSTRACT}

Precise control over composition, morphology and size of porphyrin-based metal-organic frameworks is challenging but the extension of these hybrid materials will enable the creation of novel electrochemiluminescence (ECL) emitters. The coordination of various entities are made from $\mathrm{Zn}^{2+}$ ions and meso-tetra(4-carboxyphenyl)porphine (TCPP), modulated by both solvent and bathophenanthrolinedisulfonic acid disodium salt (BPS) as capping agent, resulting in limited crystal growth of $\mathrm{Zn}-\mathrm{TCPP}$ in $\mathrm{DMF} / \mathrm{H}_{2} \mathrm{O}(V / V, 1: 1)$ and the formation of nanoscale TCPP-Zn-BPS. The role of BPS is also evaluated using Zn-TCPP and BPS-Zn-TCPP as control, prepared in the absence of BPS and different coordinating sequence of ligands, respectively. The newly obtained TCPP-Zn-BPS exhibits a variety of different morphologies, as well as, spectral, and optoelectronic properties. The ECL behavior of the TCPP-Zn-BPS is investigated by using $\mathrm{H}_{2} \mathrm{O}_{2}$ as co-reactant. The amplification of ECL is further studied by ECL spectroscopies and cyclic voltammetry, with the corresponding mechanism proposed.

KEYWORDS: $\quad$ Electrochemiluminescence; coordination modulation; meso-tetra(4-carboxyphenyl)porphine (TCPP); bathophenanthrolinedisulfonic acid disodium salt (BPS) 


\section{INTRODUCTION}

Electrochemiluminescence (ECL) is a fairly recent analytical technique that combines electrochemistry and chemiluminescence, and it is widely applied in various fields of analytical chemistry due to its good stability, high sensitivity, low detection limit, wide linear range, simple operation and rapid response analysis. ${ }^{1-8}$ Porphyrin as a conjugated molecule with $18 \pi$-electrons, whose structure is macrocyclic and composed of four pyrroles, exhibits unique biological, optical and electron transfer properties. ${ }^{9-12}$ Porphyrin compounds are popular as luminescent materials because they have large conjugated ring structures with both dominant rigidity and auxiliary flexibility, and the electrons in the ring have large fluidity as well as good stability. ${ }^{13-18}$ The most remarkable chemical property of the porphyrin system is its good coordination ability. The orientation of ligand interaction, steric hindrance and terminal moieties of porphyrin molecules can be controlled. ${ }^{19}$ In addition, these unique structures can be functionalized in the design of various application fields.

In previous work, we produced nano-crystallized porphyrin-based materials and their use in photovoltaic analysis. Initially, we combined porphyrins with nanomaterials, such as the following: (1) composite nanomaterials: a CoPPIX@ $\mathrm{C}_{3} \mathrm{~N}_{4}$ complex synthesized through $\pi-\pi$ stacking between cobalt proto-porphyrin IX (CoPPIX) and ultrathin carbon nitride nanosheets $\left(\mathrm{C}_{3} \mathrm{~N}_{4}\right) ;{ }^{20}$ with the assistance of laponite nanolayers, zinc proto-porphyrin IX (ZnPPIX) was fixed and assembled upon the nanoclay surface $;^{21}$ (2) through the surfactant-assisted self-assembly method: a 
hexagonal prism self-assembled ZnTPyP (SA-ZnTPyP) with even dimensions was synthesized with sodium dodecyl sulfate (SDS), which is an amphiphilic surfactant, acting as a "soft template". ${ }^{22} \mathrm{Zn}-\mathrm{N}$ axial coordination among pyridyl ligands is predominant in the structure of SA-ZnTPyP; aided by different surfactants, the assembly process and the subsequent optical and electrical properties of different porphyrin-assembly structures synthesized under different driving forces were studied; $^{23}$ (3) exploration of porphyrin-based MOFs: zinc tetrakis(carboxyphenyl)-porphyrin (ZnTCPP) with strong chelating ability was utilized to coordinate with zirconium(IV) chloride $\left(\mathrm{ZrCl}_{4}\right)$ to construct a metal-organic framework (MOF) structure and a novel immunosensor based on the obtained MOF was prepared to detect phosphoprotein. ${ }^{24}$ The enhanced ECL signals was due to the ${ }^{1} \mathrm{O}_{2}$ produced via the catalysis reaction of the active $\mathrm{ZnTCPP}$ center.

The synthesized porphyrin-based MOFs are too large to be suitable as biological probes. Therefore, it is useful to further reduce their size in the nanometer scale. The size-controlled synthesis of the porphyrin-based assembly system usually depends on the precise control over nucleation, growth and the formation development of the porphyrin-metal complex on specific substrates. ${ }^{25}$ Various strategies have been used in the past, such as the initiation solvent, surfactant-assisted synthesis, hard templates, and coordination modulation protocols, to produce nanoscale metal complexes. ${ }^{26-29}$ Inspired by the size modulation of MOFs, capping agents can be introduced to control the morphology of the porphyrin-based complex. Common capping agents for regulating growth and controlling final particle size include starch, glucose, albumin, 
surfactants and the like. ${ }^{30-32}$ In addition, the capping agent can also modify the surface properties of the material. For example, Phan et al. found that the oxidation state of the capping ligand determines the spatial localization of the subsequent shell on the colloidal nanoparticles. ${ }^{33}$ Therefore, it is meaningful to choose a capping agent that can control the size of the morphology and assist in enhancing the photoelectric properties of the porphyrin. BPS is a good such chelating reagent that can easily coordinate with metal ions to form a stable structure. ${ }^{34}$ Moreover, BPS has good photoelectric activity, ${ }^{35}$ whiles the choice of a capping agent exhibiting good optical and electrical properties makes it possible to impart new optical properties to the product. In this work, for the first time, we use BPS as a coordination modulator to control the growing Zn-TCPP entity through an effective competition. The nanosized TCPP-Zn-BPS was obtained via the solvothermal process, and used to modify electrodes and its ECL behavior examined for the first time.

\section{EXPERIMENT SECTION}

\section{Reagents and Materials}

Meso-Tetra(4-carboxyphenyl)porphine (TCPP) was produced by J\&K Scientific Inc.(Shanghai, China). Bathophenanthrolinedisulfonic acid disodium salt (BPS), zinc chloride $\left(\mathrm{ZnCl}_{2}\right)$ and tetraoctylammonium bromide (TOAB) were purchased from Alfa Aesar Chemicals Co. Ltd. (Shanghai, China). All other chemicals were at the grade of analytical purity and were used directly without further treatment. 
Throughout the whole work, ultrapure water was used as the water source, which was fabricated by a Millipore water purification system ( $\geq 18 \mathrm{M} \Omega$, Milli-Q, Millipore).

\section{Measurements characterization}

A MPI-EII multifunctional electrochemical and chemiluminescent analytical system (Xi'an Remex Analytical Instrument Co.,Ltd., China) was employed for ECL signal acquisition, and the emission window was located above the photomultiplier tube with a bias voltage of $1000 \mathrm{~V}$. A CHI $832 \mathrm{C}$ electrochemical workstation (CH Instrument) was utilized to investigate cyclic voltammetry (CV) measurements. The fluorescence spectra were recorded through a fluorescence spectrophotometer (Edinburgh Analytical Instruments, FLS920) and it was also used together with a CHI 832C electrochemical workstation to obtain ECL spectra. We used a XL-30E scanning electron microscope (SEM) to characterize the morphology of the nanomaterials. Infrared spectra and UV-visible absorption spectra were collected by a TENSOR Model 27 FT-IR spectrometer and a UV-vis spectrophotometry (UV-3600, Shimadzu, Japan), respectively. A typical three electrode system, a saturated calomel electrode, a Pt wire electrode and a glassy carbon electrode (GCE) were used as the reference, counter and working electrodes, respectively, and these were used for all the involved electrochemical experiments in this work. GCEs with a diameter of 5 mm were first polished by $0.3 \mu \mathrm{m}$ alumina powders, followed by $0.05 \mu \mathrm{m}$ alumina powders. Then, the electrodes are ultrasonically treated with acetone, alcohol and double distilled water in turn to obtain a mirror finish. The scan rate of the ECL measurement was $50 \mathrm{mV} \mathrm{s}^{-1}$ and the scan range was from 0.0 to $-1.7 \mathrm{~V}$. 


\section{Preparation of TCPP-Zn-BPS, Zn-TCPP and BPS-Zn-TCPP nanostructures}

TCPP-Zn-BPS was synthesized according to the protocol described as follows: TCPP, $\mathrm{ZnCl}_{2}$ and BPS were dissolved in $\mathrm{DMF} / \mathrm{H}_{2} \mathrm{O}(V / V, 1: 1) .2 \mathrm{~mL}$ of TCPP $(1 \mathrm{mM})$ was initially added into $2 \mathrm{~mL}$ of $\mathrm{ZnCl}_{2}\left(5 \mathrm{mM}\right.$,) with continuous stirring at $75{ }^{\circ} \mathrm{C}$ for 1h. Subsequently, $2 \mathrm{~mL}$ of BPS (4 mM) was added dropwise under stirring conditions and the solution was continuously stirred for 24 hours. The resulting nanostructure was gathered by centrifuging at $13000 \mathrm{rpm}$ and washed three times with $\mathrm{DMF} / \mathrm{H}_{2} \mathrm{O}$ $(V / V, 1: 1)$. Finally, the sample powder was obtained by a vacuum freeze dryer. The product was denoted as TCPP-Zn-BPS. For the control trials, the Zn-TCPP and BPS-Zn-TCPP were also synthesized following the same protocol in the absence of BPS and presence of reverse order of BPS and TCPP, respectively.

\section{Preparation of as-prepared nanostructures-based electrode.}

$1.0 \mathrm{mg}$ nanostructures (TCPP-Zn-BPS, Zn-TCPP and BPS-Zn-TCPP) were dispersed in $1 \mathrm{~mL}$ water and ultrasonic dispersion for 5 mins. The nanostructures modified GCE was prepared by the coating $20 \mu \mathrm{L}$ of TCPP-Zn-BPS solution on the electrode surface and airdrying at room temperature. In order to enhance the stability of the electrode, $10 \mu \mathrm{L}$ of TOAB solution, which is prepared by dispersing $10 \mathrm{mmol}$ of TOAB in $1 \mathrm{~mL}$ of ethanol under sonication, coated the electrode surface.

\section{RESULTS AND DISCUSSION}

\section{Solvation effect}


TCPP contains four terminal carboxyphenyl groups at the terminus of porphyrin. On account of the regnant $\pi-\pi$ stacking interaction of the porphyrin ring, TCPP can easily aggregate in the aqueous solution, which can lead to the embedded active sites of porphyrin molecules. ${ }^{36}$ Whereas, in an aprotic solvent, namely the DMF, TCPP molecules can be connected with each other through the coordination of zinc metal ions and carboxyl groups to form 2D layered sheets. Simultaneously, the TCPP ligands are metallized by central $\mathrm{Zn}^{2+}$ ions by $\mathrm{Zn}-\mathrm{N}$ ligations. The layered sheets are further stacked in dislocations and finally, 3D MOF structures were formed with $\mathrm{Zn}^{2+}$ ions in the centers of porphyrin rings aligned with $\mathrm{Zn}^{2+}$ ions at the outer core. The introduction of secondary ligands can control the size growth of nanocrystals via their competitive coordination with metals. Herein, the hydro-soluble BPS, which has two exposed sulfonate groups, can be rapidly chelated with zinc ions in aqueous solution through $\mathrm{Zn}-\mathrm{N}$ ligations and competitively occupy the coordination orbit of metal ions. In a nonprotic solvent, the solubility of BPS is poor and its binding ability is limited. ${ }^{37}$ Therefore, the assembling microenvironment can be adjusted by controlling the volumetric ratio of protic and nonprotic solvent, allowing the competitive chelating ability between the $\mathrm{Zn}^{2+}$ ions and different ligands (TCPP and BPS), thereby adjusting the overall assembly of the nascent structure and thus modulating various formations of porphyrin-based MOFs. In this work, we synthesized TCPP-Zn-BPS with DMF, pure water and a mixed solvent of DMF and water at volumetric ratios of 2:1, 1:1 and 1:2, respectively. Different TCPP-Zn-BPS /GCE were prepared by coating $20 \mu \mathrm{L}$ TCPP-Zn-BPS solution samples $\left(1 \mathrm{mg} \mathrm{mL}^{-1}\right)$ on the GCE surface. 10 
mmol L $\mathrm{L}^{-1}(\mathrm{pH} 7.0)$ HEPES containing $0.3 \mathrm{~mol} \mathrm{~L}^{-1} \mathrm{KCl}$ solution was used as electrolyte during the ECL investigation of TCPP-Zn-BPS /GCE with $0.05 \mathrm{M} \mathrm{H}_{2} \mathrm{O}_{2}$ acting as co-reactant. As displayed in Figure 1A, the TCPP-Zn-BPS structure synthesized with a solvent volumetric ratio of 2:1 demonstrated the best ECL performance with an intensity peak at about 14000 a.u. Structures synthesized in $\mathrm{DMF} / \mathrm{H}_{2} \mathrm{O} \quad(V / V, \quad 1: 1), \quad \mathrm{DMF} / \mathrm{H}_{2} \mathrm{O} \quad(V / V, 2: 1), \quad \mathrm{H}_{2} \mathrm{O}$ and $\mathrm{DMF}$, provided the corresponding light intensities at about 11200, 8300, 8100 and 6000 a.u., respectively. However, when comparing with Zn-TCPP /GCE (curve a in Figure 1B and 1C), TCPP-Zn-BPS synthesized in solvent, in which volumetric ratio of DMF to water is 2:1, does not differ in ECL enhancement behavior (curve b in Figure 1B). Compared with Zn-TCPP synthesized with a solvent volumetric ratio of 1:1 (curve b in Figure 1C), the ECL intensity of TCPP-Zn-BPS showed 2-fold enhancement. The ECL responses of the modified electrode, which is obtained during a continuous potential scan, show good constant and stable signals. The intensity is just $83 \%$ of the original intensity after nine cycles, and the relative standard deviation (RSD) is just $1.5 \%$ (Figure 1D), demonstrating the good stability and reproducibility of the proposed ECL system. We suspect that BPS has poor solubility in nonprotic solvent, and the complexing ability with $\mathrm{Zn}^{2+}$ is weak. $\mathrm{Zn}^{2+}$ will preferentially coordinate with TCPP in high composition of nonprotic solvent. That is, the coordination of $\mathrm{Zn}^{2+}$ and TCPP is dominant in $\mathrm{DMF} / \mathrm{H}_{2} \mathrm{O}(\mathrm{V} / \mathrm{V}, 2: 1)$, while BPS is ineffective. When the volumetric ratio is $1: 1$, as the composition of protic solvent increases, the complexing ability of BPS and $\mathrm{Zn}^{2+}$ becomes stronger, and the chelating abilities of BPS and TCPP to $\mathrm{Zn}^{2+}$ 
are comparable. Thus, BPS can be used as a good capping agent for controlling the size of the assembly structure and the derived TCPP-Zn-BPS nanomaterial obtained enhanced ECL performance, when the solvent ratio is carefully chosen.

\section{[Figure 1]}

In order to confirm the role of BPS as a capping agent, the morphological characterization of the synthesized nanostructures was recorded by scanning electron microscopy (SEM). As is shown in Figure 2, the two Zn-TCPP structures synthesized in $\mathrm{DMF} / \mathrm{H}_{2} \mathrm{O}(V / V, 2: 1)$ and $\mathrm{DMF} / \mathrm{H}_{2} \mathrm{O}(V / V, 1: 1)$ exhibit similar rod-like structures with different lengths (Figure 2A and 2B). It was shown that the solvation effect has little effect on the chelation of $\mathrm{Zn}^{2+}$ and TCPP. For TCPP-Zn-BPS synthesized in $\mathrm{DMF} / \mathrm{H}_{2} \mathrm{O}(V / V, 2: 1)$, the morphology has not changed significantly. In this solvent, the chelation between $\mathrm{Zn}^{2+}$ and TCPP is dominant, and the obtained structure is still a "rod-like" structure with the average length of $2 \mu \mathrm{m}$ and the diameter of $200 \mathrm{~nm}$ (Figure 2C), verifying the previous estimate that BPS does not work well in solvents with high aprotic concentrations. The morphology of synthesized TCPP-Zn-BPS in $\mathrm{DMF} / \mathrm{H}_{2} \mathrm{O}(V / V, 1: 1)$ exists as nanorods at various lengths $(100 \mathrm{~nm}$ to $800 \mathrm{~nm})$ with an average length at about $300 \mathrm{~nm}$ and a diameter of $50 \mathrm{~nm}$ (Figure 2D). The size of TCPP-Zn-BPS is significantly smaller because the solubility of BPS is increased in this solvent, and the coordination ability with $\mathrm{Zn}^{2+}$ is also increased. At this time, BPS can compete with TCPP in binding $\mathrm{Zn}^{2+}$ and the complexation of $\mathrm{Zn}^{2+}$ and TCPP is thus disturbed. So that a nanoscale TCPP-Zn-BPS structure can be obtained with BPS acting as a capping agent. 
[Figure 2]

\section{Confirmation of the presence of BPS in the newly obtained nanostructure}

Since BPS acts as a capping agent, it should appear at the end of the final structure. In order to verify whether BPS is really chelated, we studied the spectroscopic properties of the structure synthesized in $\mathrm{DMF} / \mathrm{H}_{2} \mathrm{O}(V / V, 1: 1)$. The X-ray diffraction (XRD) spectra, UV-visible (UV-vis) spectra and Fourier transform (FT-IR) infrared spectroscopy spectra were recorded to analyze the structure of the MOFs and the role of BPS throughout the process. The XRD data showed single crystal patterns with main peaks between $5^{\circ}$ and $35^{\circ}$. The XRD spectrum of TCPP (curve a in Figure S1A) has no obvious peaks, indicating that the structure is disordered and amorphous. For Zn-TCPP (curve a in Figure 3A), the shape of XRD peaks is sharp, demonstrating its crystal structure. There is no characteristic peak of BPS (curve b in Figure S1A) in the XRD spectrum of TCPP-Zn-BPS (curve $b$ in Figure 3A), which may be difficult to prove the existence of BPS in the synthesized material. Compared with Zn-TCPP, there is little change in the XRD peaks of TCPP-Zn-BPS. This indicates that the resulting TCPP-Zn-BPS is still a porphyrin-based MOF based on Zn-TCPP structure. And whether BPS is present or not, requires needs further verification.

[Figure 3]

For the UV-vis spectrum of the TCPP, there is a strong absorption peak at $416 \mathrm{~nm}$, pertaining to a strong Soret band (B-band), and four more absorption peaks (Q bands) at 513, 545, 590 and $645 \mathrm{~nm}$ (curve a in Figure S1B). BPS does not show obvious 
UV-visible absorption peaks (curve b in Figure S1B). Regarding Zn-TCPP (curve a in Figure 3B), the position of the Soret band is slightly shifted and is located at $422 \mathrm{~nm}$, while the Q bands occur red-shifted, and are situated at 535, 571, 613 and $663 \mathrm{~nm}$. The red-shift phenomenon is caused by a reduction in energy level transition of the porphyrin rings due to the conjugation between the porphyrin substituents and the porphyrin rings. ${ }^{38}$ For TCPP-Zn-BPS (curve b in Figure 3B), two Soret bands appear at 410 and $420 \mathrm{~nm}$, and the matched Q bands lie in 532, 567, 606 and $660 \mathrm{~nm}$. The split of the Soret band may be caused by $\mathrm{J}$ aggregation. The UV-vis absorption peak has changed significantly, probably because of the chelation of BPS. At the same time, the absorption peak of the B-band of TCPP-Zn-BPS is observed as enhanced, which we assume is due to the fact that the nano-crystallization of the material provides greater exposure of the porphyrin groups.

In order to further verify the existence of BPS in TCPP-Zn-BPS, Fourier transform infrared spectroscopy (FTIR) spectra were captured. We can observe a strong $\mathrm{C}=\mathrm{O}$ stretching vibration at around $1688 \mathrm{~cm}^{-1}$ in the FT-IR spectrum of TCPP (curve a in Figure S1C), at $1667 \mathrm{~cm}^{-1}$ of Zn-TCPP (curve a in Figure 3C) and at $1675 \mathrm{~cm}^{-1}$ of TCPP-Zn-BPS (curve b in Figure 3C), which is consistent with the reports in the literature. ${ }^{39}$ The stretching vibration of $\mathrm{C}=\mathrm{O}$ in TCPP-Zn-BPS is greatly enhanced compared with $\mathrm{C}=\mathrm{O}$ in original TCPP and $\mathrm{Zn}-\mathrm{TCPP}$, indicating the strong interaction of $\mathrm{C}=\mathrm{O}$ group in TCPP with $\mathrm{Zn}^{2+}$ ions. The FT-IR spectrum of $\mathrm{Zn}$-TCPP (curve a in Figure 3C) does not differ much from $\mathrm{Zn}$-TCPP that was synthesized in DMF/ $\mathrm{H}_{2} \mathrm{O}$ (V/V, 2:1) (curve a in Figure S2B). For TCPP-Zn-BPS (curve b in Figure 3C), peaks 
at $2665 \mathrm{~cm}^{-1}$ and $2535 \mathrm{~cm}^{-1}$ were attributed to the $\mathrm{O}-\mathrm{H}$ stretching vibration in water molecules. While the peak at $1286 \mathrm{~cm}^{-1}$ was consistent with the infrared characteristic peak of BPS, located at $1186 \mathrm{~cm}^{-1}$ (curve b in Figure S1C), which is the characteristic absorption peak of sulfonic acid group of BPS, ${ }^{40}$ indicating that BPS does exist in the final structure. Absorption peak at $1286 \mathrm{~cm}^{-1}$ is the characteristic of $\mathrm{C}-\mathrm{N},{ }^{41}$ which we attribute to the $\mathrm{C}-\mathrm{N}$ stretching vibration absorption peak of BPS. There is no significant difference between the UV-vis and FT-IR spectra of Zn-TCPP and TCPP-Zn-BPS synthesized in $\mathrm{DMF} / \mathrm{H}_{2} \mathrm{O}(V / V, 2: 1)$ (See Figure $\mathrm{S} 2$ for details.). In addition, we wondered whether the sequence of ligand addition will affect the formation of the entire structure. Therefore, BPS-Zn-TCPP, which is synthesized by first adding BPS and then adding TCPP one hour later, was prepared, and its ECL properties were investigated. As displayed in Figure S3, compared with Zn-TCPP /GCE and TCPP-Zn-BPS /GCE, BPS-Zn-TCPP /GCE had the worst ECL performance and the ECL intensity was about 3000a.u. To explain this phenomenon, morphology and spectroscopy properties were characterized. The BPS-Zn-TCPP exhibited the morphology of "thick sheet-like" structures covered with nanorods of about $700 \mathrm{~nm}$ in size, with a typical size of the sheet at about $6 \mu \mathrm{m} \times 6 \mu \mathrm{m}$ (Figure S4A). The XRD peaks of BPS-Zn-TCPP (Figure S4B) have changed greatly in number and position, indicating that the crystal structure has changed. The Soret band of BPS-Zn-TCPP (Figure S4C) in the UV-visible spectrum is located at $422 \mathrm{~nm}$. Besides, the four weak Q absorption bands from TCPP turned into just three and were located at $559 \mathrm{~nm}, 603 \mathrm{~nm}$ and $660 \mathrm{~nm}$. The FT-IR spectra of Zn-TCPP (curve a in 
Figure 3C) is not dramatically different from that of BPS-Zn-TCPP (Figure S4D), except two weak peaks appear at about $2921 \mathrm{~cm}^{-1}$ and $2950 \mathrm{~cm}^{-1}$, which is consistent with the infrared characteristic peak of BPS, which are located at $3064 \mathrm{~cm}^{-1}$ and 3096 $\mathrm{cm}^{-1}$ (curve $\mathrm{b}$ in Figure $\mathrm{S} 1 \mathrm{C}$ ). The change in the order of ligand addition causes great variation in ECL performance and spectral properties of the resulting composite, which is related to the structure formed.

According to the aforementioned experimental results, with a volumetric ratio of DMF to $\mathrm{H}_{2} \mathrm{O}$ at 1 to 1 , the nanoscale of TCPP-Zn-BPS can be successfully obtained by ligand competition. The resulting TCPP-Zn-BPS is still a porphyrin-based MOF with a good distribution of BPS on the MOF, and the presence of BPS does not affect the crystal structure of the MOF. Therefore, we may venture into estimating the structure formation processes of Zn-TCPP, TCPP-Zn-BPS and BPS-Zn-TCPP. As shown in Scheme 1, $\mathrm{Zn}$-TCPP, the TCPP and $\mathrm{ZnCl}_{2}$ formed a $2 \mathrm{D}$ square grid through coordination of four carboxyphenyl groups at the outer core of TCPP and $\mathrm{Zn}^{2+}$. Every four carboxyl groups from four TCPP molecules are combined with two $\mathrm{Zn}^{2+}$. At the same time, zinc ions enter the middle of porphyrin rings and are immobilized in the center of the porphyrin by $\mathrm{Zn}-\mathrm{N}$ bond. These grids are stacked together by $\pi-\pi$ interaction and each layer is translated by $(1 / 2,1 / 2,1 / 2)$ relative to the adjacent layers, that is, the middle $\mathrm{Zn}^{2+}$ ions of porphyrin rings are aligned with the $\mathrm{Zn}^{2+}$ ions linked with carboxyphenyl groups. As for TCPP-Zn-BPS, after injection of BPS, BPS competes with TCPP and binds to zinc atoms on the edge of grids. Simultaneously, the BPS molecules is disordered as slightly above or below the porphyrin plane, 
which plays a key role for the controlled growth of the structure, causing the formation of nanoscale TCPP-Zn-BPS. The steric hindrance of BPS may weaken the $\pi-\pi$ stacking between porphyrins This allows the synthesized material to have a large specific surface area, and the active site can be sufficiently exposed. Therefore, TCPP-Zn-BPS can have better contact with the co-reactant in the electrolyte, thereby having better ECL performance. For BPS-Zn-TCPP, BPS is reacted with $\mathrm{ZnCl}_{2}$ in advance (Scheme S1). The post-added TCPP can only be combined with the previous structure by $\pi-\pi$ stacking, which leads to the active sites of the formed structure not being fully exposed. This is why BPS-Zn-TCPP has the worst ECL performance.

[Scheme 1]

\section{The role of BPS}

Since we have determined that BPS as a capping agent exists in the structure of TCPP-Zn-BPS, we wonder whether BPS will give new optics and electrical properties of the synthesized materials. The ECL intensity of Zn-TCPP/GCE is around 6000 a.u. However, the ECL signals of TCPP-Zn-BPS/GCE are constant during a continuous potential scan and the relative standard deviation (RSD) is just 1.5\%. This demonstrates the ECL system has good stability and repeatability, and can be further used to manufacture sensors.

The Zn-TCPP and TCPP-Zn-BPS exhibit good fluorescence performance. As shown in Figure 4, the optimum excitation wavelength of them is $416 \mathrm{~nm}$, and the obtained emission peaks in the spectrum are situated at 608 and $658 \mathrm{~nm}$. The optimum 
excitation was obtained with the wavelength $608 \mathrm{~nm}$ working as measure peak for its stronger fluorescence response. By comparison we can know that when the concentration is same, both fluorescence excitation and emission intensities of TCPP-Zn-BPS (curve b in Figure 4) are 26 times that of Zn-TCPP (curve a in Figure 4). It is proved that the porphyrin still has fluorescence characteristics after the reaction, and it has a satisfactory improvement compared with the porphyrin monomers.

\section{[Figure 4]}

To further study the electrical properties of porphyrin-based MOFs, the electrochemical behaviors of various modified electrodes were studied. All the electrochemical studies were performed in a $\mathrm{N}_{2}$-saturated atmosphere. Figure 5 exhibits the corresponding $\mathrm{CV}$ curves of different modified electrodes measured in $\mathrm{pH}$ 7.0 HEPES with $0.3 \mathrm{~mol} \mathrm{~L} \mathrm{~L}^{-1} \mathrm{KCl}$ solution in the absence and presence of $0.05 \mathrm{M}$ $\mathrm{H}_{2} \mathrm{O}_{2}$. In the absence of $0.05 \mathrm{M} \mathrm{H}_{2} \mathrm{O}_{2}$, for TCPP/GCE (curve a in Figure 5B), the reduction processes are discovered at $-0.608,-0.995,-1.269$ and $-1.446 \mathrm{~V}$ and the oxidation processes are located at $-0.594,-0.965,-1.211$ and $-1.385 \mathrm{~V}$. According to the direct electrochemistry of porphyrins, it is speculated that the deprotonated TCPP went through a gradual four-electron reduction: $\left[\mathrm{H}^{+}\right]_{2} \mathrm{TCPP}^{2+} \rightarrow\left[\mathrm{H}^{+}\right] \mathrm{TCPP}^{\bullet+} \rightarrow$ $\mathrm{TCPP}^{\circ}$ (unsubstituted) $\rightarrow[\mathrm{H}] \mathrm{TCPP}^{\bullet^{-}} \rightarrow[\mathrm{H}]_{2} \mathrm{TCPP}^{2-}$. In comparison, the reduction peaks of $\mathrm{Zn}-\mathrm{TCPP} / \mathrm{GCE}$ are found at $-0.609,-1.011,-1.203$ and $-1.371 \mathrm{~V}$ (curve a in Figure $5 \mathrm{C}$ ), corresponding to $\left[\mathrm{Zn}^{2+}\right] \mathrm{TCPP} \rightarrow\left[\mathrm{Zn}^{\bullet+}\right] \mathrm{TCPP} \rightarrow\left[\mathrm{Zn}^{0}\right] \mathrm{TCPP} \rightarrow$ $\left[\mathrm{Zn}^{0}\right] \mathrm{TCPP}^{\bullet-} \rightarrow\left[\mathrm{Zn}^{0}\right] \mathrm{TCPP}^{2-}$. TCPP-Zn-BPS exhibits the similar behaviour to that of 
$\mathrm{Zn}$-TCPP with the reduction peaks located at $-0.618,-1.013,-1.202$ and $-1.371 \mathrm{~V}$ and the oxidation processes located at $-0.594,-0.965,-1.211$ and $-1.385 \mathrm{~V}$. (curve a in Figure 5D). For the redox signal of $\left[\mathrm{Zn}^{\bullet+}\right] \mathrm{TCPP} /\left[\mathrm{Zn}^{0}\right] \mathrm{TCPP}$, $\left[\mathrm{Zn}^{0}\right] \mathrm{TCPP} /\left[\mathrm{Zn}^{0}\right] \mathrm{TCPP}^{\bullet-}$ and $\left[\mathrm{Zn}^{0}\right] \mathrm{TCPP}^{\bullet-} /\left[\mathrm{Zn}^{0}\right] \mathrm{TCPP}^{2-}, \mathrm{d} E_{\mathrm{p}}$ are $0.062,0.069$ and $0.011 \mathrm{~V}$, respectively. The small peak potential difference indicates a fairly high reversibility of the superficial redox couples. However, the peak potential difference of $\left[\mathrm{Zn}^{2+}\right] \mathrm{TCPP} /\left[\mathrm{Zn}^{\bullet+}\right] \mathrm{TCPP}$ is much larger $(0.325 \mathrm{~V})$, indicating a relatively worse reversibility. In contrast to the original TCPP/GCE, we found that the two reduction peaks of two porphyrin-based MOFs have a large shift, which are attributable to the progress of $\left[\mathrm{Zn}^{0}\right] \mathrm{TCPP} /\left[\mathrm{Zn}^{0}\right] \mathrm{TCPP}^{\bullet-}$ and $\left[\mathrm{Zn}^{0}\right] \mathrm{TCPP}^{\bullet-} /\left[\mathrm{Zn}^{0}\right] \mathrm{TCPP}^{2-}$. With the existence of $0.05 \mathrm{M} \mathrm{H}_{2} \mathrm{O}_{2}$, it is obvious that different electrodes have different catalytic effects on $\mathrm{H}_{2} \mathrm{O}_{2}$. BPS/GCE shows strong current response (Figure 5A), which is proved that BPS has a good catalytic effect on $\mathrm{H}_{2} \mathrm{O}_{2}$. For TCPP/GCE, only the cathodic peak current of both the $\mathrm{TCPP}^{\circ} /[\mathrm{H}] \mathrm{TCPP}^{\bullet-}$ and $[\mathrm{H}] \mathrm{TCPP}^{\bullet-} /[\mathrm{H}]_{2} \mathrm{TCPP}^{2-}$ increase in the presence of $\mathrm{H}_{2} \mathrm{O}_{2}$ (curve $b$ in Figure 5B). As for Zn-TCPP/GCE and TCPP-Zn-BPS/GCE, with the presence of $\mathrm{H}_{2} \mathrm{O}_{2}$, all the cathodic peak current increase (curve $\mathrm{b}$ in Figure 5C and 5D). This illustrate that with the assistance of metallic zinc, the material can catalyze the $\mathrm{H}_{2} \mathrm{O}_{2}$ at a lower potential, resulting in more production of $\bullet \mathrm{OH}$, which is the key substance for ECL luminescence. Simultaneously, due to good catalytic action of ligand BPS and the concerted catalysis of ligand BPS and ligand TCPP, the TCPP-Zn-BPS/GCE has the best catalytic performance for $\mathrm{H}_{2} \mathrm{O}_{2}$, resulting in abundant production of $\cdot \mathrm{OH}$. Combined with the above mentioned ECL 
behaviour, we can conclude that the existence of $\left[\mathrm{Zn}^{0}\right] \mathrm{TCPP} /\left[\mathrm{Zn}^{0}\right] \mathrm{TCPP}^{\bullet-}$ transition, $\left[\mathrm{Zn}^{0}\right] \mathrm{TCPP}^{\bullet-} /\left[\mathrm{Zn}^{0}\right] \mathrm{TCPP}^{2-}$ transition and $\bullet \mathrm{OH}$ groups, is an critical role in the ECL system.

[Figure 5]

Simultaneously, EIS measurements were carried out to further study the role of BPS with $\mathrm{Fe}(\mathrm{CN})_{6}^{4-/ 3-}$ as a sensitive redox probe (Figure 6). As shown, the charge-transfer resistance $\left(R_{c t}\right)$, that is, the diameter of the semicircle in the impedance spectra, which is related to the capability of electron transfer of a ferricyanide-redox probe between the electrolyte and the electrode, significantly decreased after introducing BPS as a capping agent. This demonstrates that the electron transfer can be highly improved by BPS.

\section{[Figure 6]}

\section{ECL signal-amplification mechanism}

One of the most important factors in enhanced ECL behaviours is the innovative illuminator. We need to determine the luminophore in the system to understand the its luminous mechanism, and to explain the related effect of porphyrins. Hence, utilizing a fluorescence spectrometer, the ECL emission spectrum of Zn-TCPP and TCPP-Zn-BPS in pH 7.0 HEPES with $0.3 \mathrm{~mol} \mathrm{~L}^{-1} \mathrm{KCl}$ solution and $0.05 \mathrm{M} \mathrm{H}_{2} \mathrm{O}_{2}$ was surveyed. As shown in Figure 7, for both Zn-TCPP and TCPP-Zn-BPS, the scope of the ECL emission (red curve in Figure 7A and 7B) is mainly from 400 to $700 \mathrm{~nm}$ and 
the maximum wavelength is located at about $570 \mathrm{~nm}$. This is in accordance with the luminous characteristics of porphyrin reported in the literature. Combined with PL spectra (black curve in Figure 7A and 7B), we can draw the conclusion that porphyrins are the luminophore. Figure 8 exhibits the ECL behaviours of TCPP-Zn-BPS/GCE in electrolyte containing different dissolved oxygen concentrations. In the absence of $0.05 \mathrm{M} \mathrm{H}_{2} \mathrm{O}_{2}$, the ECL intensity under the $\mathrm{O}_{2}$-saturated conditions is up to 1500 a.u. (curve c in Figure 8A), which is 1.4 times higher than that under air-saturated (curve $\mathrm{b}$ in Figure 8A) and 15.5 times higher than that under $\mathrm{N}_{2}$-saturated conditions (curve a in Figure 8A). This indicates that oxygen also has a synergistic effect on the enhancement of ECL performance. In the presence of $0.05 \mathrm{M} \mathrm{H}_{2} \mathrm{O}_{2}$, there is no significant difference in ECL intensity with or without oxygen (Figure 8B). This indicates that when $\mathrm{H}_{2} \mathrm{O}_{2}$ works as the co-reactant, the effect of oxygen is negligible.

[Figure 7]

\section{[Figure 8]}

The mass, structure, as well as photochemical properties of the luminophore determine the intensity of the ECL signals. As mentioned above, the ECL emission of $\mathrm{Zn}$-TCPP is not strong, because in that structure, $\pi-\pi$ stacking plays a dominant influencing factor, resulting in the coverage of active TCPP and metal ion $\mathrm{Zn}^{2+}$, which further causes the active sites to have reduced exposure with the co-reactant $\mathrm{H}_{2} \mathrm{O}_{2}$. As for TCPP-Zn-BPS, the addition of BPS prevents the endless growth of TCPP and 
$\mathrm{Zn}^{2+}$, resulting in a material with a larger specific surface area enabling the presence of increased number of exposed active sites, thus enabling a better ECL signal.

Based on the experimental results, as well as the above assertions, the following response equations are used to describe the possible ECL mechanism with $\mathrm{H}_{2} \mathrm{O}_{2}$ as the co-reactant:

$$
\begin{aligned}
& \mathrm{H}_{2} \mathrm{O}_{2}+\mathrm{e}^{-} \rightarrow \bullet \mathrm{OH}+\mathrm{OH}^{-} \\
& {\left[\mathrm{Zn}^{2+}\right] \mathrm{TCPP}+\mathrm{e}^{-} \rightarrow\left[\mathrm{Zn}^{\bullet+}\right] \mathrm{TCPP}} \\
& {\left[\mathrm{Zn}^{\bullet+}\right] \mathrm{TCPP}+\mathrm{H}_{2} \mathrm{O}_{2} \rightarrow\left[\mathrm{Zn}^{2+}\right] \mathrm{TCPP}+\bullet \mathrm{OH}+\mathrm{OH}^{-}} \\
& {\left[\mathrm{Zn}^{\bullet+}\right] \mathrm{TCPP}+\mathrm{e}^{-} \rightarrow\left[\mathrm{Zn}^{0}\right] \mathrm{TCPP}} \\
& {\left[\mathrm{Zn}^{0}\right] \mathrm{TCPP}+\mathrm{H}_{2} \mathrm{O}_{2} \rightarrow\left[\mathrm{Zn}^{\bullet+}\right] \mathrm{TCPP}+\bullet \mathrm{OH}+\mathrm{OH}^{-}} \\
& {\left[\mathrm{Zn}^{0}\right] \mathrm{TCPP}+\mathrm{e}^{-} \rightarrow\left[\mathrm{Zn}^{0}\right] \mathrm{TCPP}^{\bullet-}} \\
& {\left[\mathrm{Zn}^{0}\right] \mathrm{TCPP}{ }^{\bullet-}+\mathrm{H}_{2} \mathrm{O}_{2} \rightarrow\left[\mathrm{Zn}^{0}\right] \mathrm{TCPP}+\bullet \mathrm{OH}+\mathrm{OH}^{-}} \\
& {\left[\mathrm{Zn}^{0}\right] \mathrm{TCPP}^{\bullet-}+\mathrm{e}^{-} \rightarrow\left[\mathrm{Zn}^{0}\right] \mathrm{TCPP}^{2-}} \\
& {\left[\mathrm{Zn}^{0}\right] \mathrm{TCPP}^{2-}+\mathrm{H}_{2} \mathrm{O}_{2} \rightarrow\left[\mathrm{Zn}^{0}\right] \mathrm{TCPP}^{\bullet-}+\bullet \mathrm{OH}+\mathrm{OH}^{-}} \\
& {\left[\mathrm{Zn}^{0}\right] \mathrm{TCPP}^{2-}+\bullet \mathrm{OH} \rightarrow\left[\mathrm{Zn}^{*}\right] \mathrm{TCPP}^{2-}+\mathrm{OH}^{-}} \\
& {\left[\mathrm{Zn}^{*}\right] \mathrm{TCPP}^{2-} \rightarrow\left[\mathrm{Zn}^{0}\right] \mathrm{TCPP}^{2-}+h v}
\end{aligned}
$$

The possible ECL mechanism with $\mathrm{O}_{2}$ as the co-reactant can be seen in supporting information (Figure S5).

\section{CONCLUSION}


In summary, we mediated the coordination between $\mathrm{Zn}^{2+}$ and TCPP, $\mathrm{Zn}^{2+}$ and BPS by solvation, and successfully synthesized a nanoscale porphyrin-based MOF, TCPP-Zn-BPS. BPS as a capping agent can effectively adjust the size of $\mathrm{Zn}$-TCPP from micron to nanoscale. Simultaneously, BPS can also be assembled at the end of $\mathrm{Zn}$-TCPP to form TCPP-Zn-BPS, and the introduction of BPS can effectively enhance the electron transport capacity. Compared with the Zn-TCPP, the TCPP-Zn-BPS has a larger specific surface area, resulting in more efficient luminophores of ECL exposed. Thereby, the enhanced ECL could be obtained. Further works should be carried out to modify the as-synthesized nanomaterials and develop the potential applications in biosensing. Our findings suggest that coordination modulation can be useful for exploring novel size-controlled porphyrin-based assembled system and in our future research we intend to concentrate on these studies.

\section{ASSOCIATED CONTENT}

\section{Supporting Information}

The Supporting Information is available free of charge at

Supporting notes: Figure S1, spectroscopic properties of TCPP and BPS; Figure S2, spectroscopic properties of Zn-TCPP and TCPP-Zn-BPS; Figure S3, ECL response of BPS-Zn-TCPP; Figure S4, characterization of BPS-Zn-TCPP; Figure S5, the possible ECL mechanism with $\mathrm{O}_{2}$ as the co-reactant; Scheme $\mathrm{S} 1$, schematic illustrations for the construction of BPS-Zn-TCPP.

\section{Notes}


The authors declare no competing financial interest.

\section{Acknowledgements}

This research was supported by National Natural Science Foundation of China (Grant No.21675086), the Fundamental Research Funds for the Central Universities (No.30918012202), “Overseas Academic Partnership Program” of Nanjing University of Technology (2019), and a project founded by the priority academic program development of Jiangsu Higher Education Institutions (PAPD). The authors wish also to acknowledge the support from the Sino-French international research network "New nanostructured materials and biomaterials for renewable electrical energy sources" for providing facilities.

\section{Reference}

(1) Hesari, M.; Ding, Z. J. Electrochem. Soc. 2016, 163, H3116-H3131.

(2) Richter, M. M, Chem. Rev. 2004, 104, 3003-3036

(3) Miao, W. Chem. Rev. 2008, 108, 2506-2553

(4) Forster, R. J.; Bertoncello, P.; Keyes, T. E. Annu. Rev. Anal. Chem. 2009, 2, 359-385.

(5) Bard, A. J.; Dekker, M. Electrogenerated Chemiluminescence, New York, 2004.

(6) Han, Z.; Yang, Z.; Sun, H.; Xu, Y.; Ma, X.; Shan, D.; Chen, J.; Huo, S.; Zhang, Z.; Du, P.; Lu, X. Angew. Chem. Int. Ed. Engl. 2019, 58, 5915-5919.

(7) Han, Z.; Zhang, Y.; Wu, Y.; Li, Z.; Bai, L.; Huo, S.; Lu, X. Anal. Chem. 2019, 91, 8676-8682.

(8) Pu, G.; Zhang, D.; Mao, X.; Zhang, Z.; Wang, H.; Ning, X.; Lu, X. Anal. Chem. 2018, 90, 5272-5279. 
(9) Dunbar, A. D.; Brittle, S.; Richardson, T. H.; Hutchinson, J.; Hunter, C. A. J Phys. Chem. B 2010, 114, 11697-11702.

(10) Wang, L.; Chen, Y.; Bian, Y.; Jiang, J. J. Phys. Chem. C 2013, 117, 17352-17359.

(11) Hod, I.; Sampson, M. D.; Deria, P.; Kubiak, C. P.; Farha, O. K.; Hupp, J. T. ACS Catal. 2015, 5, 6302-6309.

(12) Ma, T.; Pan, Z.; Miao, L.; Chen, C.; Han, M.; Shang, Z.; Chen, J. Angew. Chem. Int. Ed. Engl. 2018, 57, 3158-3162.

(13) Wang, J.; Zhong, Y.; Wang, X.; Yang, W.; Bai, F.; Zhang, B.; Alarid, L.; Bian, K.; Fan, H. Nano Lett. 2017, 17, 6916-6921.

(14) Mukherjee, G.; Thote, J.; Aiyappa, H. B.; Kandambeth, S.; Banerjee, S.; Vanka, K.; Banerjee, R. Chem. Commun. (Camb.) 2017, 53, 4461-4464.

(15) Wang, J.; Zhong, Y.; Wang, L.; Zhang, N.; Cao, R.; Bian, K.; Alarid, L.; Haddad, R. E.; Bai, F.; Fan, H. Nano Lett. 2016, 16, 6523-6528.

(16) Zhong, Y.; Wang, J.; Zhang, R.; Wei, W.; Wang, H.; Lu, X.; Bai, F.; Wu, H.; Haddad, R.; Fan, H. Nano Lett. 2014, 14, 7175-7179.

(17) Wang, W.; Shan, D.; Yang, Y.; Wang, C.; Hu, Y.; Lu, X. Chem. Commun. (Camb) 2011, 47, 6975-6977.

(18) Pu, G.; Yang, Z.; Wu, Y.; Wang, Z.; Deng, Y.; Gao, Y.; Zhang, Z.; Lu, X. Anal. Chem. 2019, 91, 2319-2328.

(19) Gottfried, J. M. Surf. Sci. Rep. 2015, 70, 259-379.

(20) Deng, S.; Yuan, P.; Ji, X.; Shan, D.; Zhang, X. ACS Appl. Mater. Interfaces 2015, 7, 543-552.

(21) Deng, S.; Zhang, T.; Ji, X.; Wan, Y.; Xin, P.; Shan, D.; Zhang, X. Anal. Chem. 2015, 87, 9155-9162.

(22) Cai, W. R.; Zhang, G. Y.; Lu, K. K.; Zeng, H. B.; Cosnier, S.; Zhang, X. J.; Shan, 
D. ACS Appl. Mater. Interfaces 2017, 9, 20904-20912.

(23) Cai, W.-R.; Cosnier, S.; Zhang, X.-J.; Marks, R.; Shan, D. Electrochim. Acta 2019, 299, 560-566.

(24) Zhang, G. Y.; Zhuang, Y. H.; Shan, D.; Su, G. F.; Cosnier, S.; Zhang, X. J. Anal. Chem. 2016, 88, 11207-11212.

(25) Van Gough, D.; Lambert, T. N.; Wheeler, D. R.; Rodriguez, M. A.; Brumbach, M. T.; Allendorf, M. D.; Spoerke, E. D. ACS Appl. Mater. Interfaces 2014, 6, 1509-1514.

(26) Costanzo, S.; Simon, G.; Richardi, J.; Colomban, P.; Lisiecki, I. J. Phys. Chem. C 2016, 120, 22054-22061.

(27) Zhang, C.; Chen, P.; Dong, H.; Zhen, Y.; Liu, M.; Hu, W. Adv. Mater. 2015, 27, 5379-5387.

(28) Zheng, X.; Kuang, Q.; Yan, K.; Qiu, Y.; Qiu, J.; Yang, S. ACS Appl. Mater. Interfaces 2013, 5, 11249-11257.

(29) Guo, H.; Zhu, Y.; Wang, S.; Su, S.; Zhou, L.; Zhang, H. Chem. Mater. 2012, 24, 444-450.

(30) Yu, J. C.; Zhao, F. G.; Shao, W.;Ge, C. W.; Li, W. S. Nanoscale 2015, 7, 8811-8818.

(31) Ajitha, B.; Kumar Reddy, Y. A.; Reddy, P. S.; Jeon, H.-J.; Ahn, C. W. RSC Adv. 2016, 6, 36171-36179.

(32) Nath, S. K.; Kalita, P. K. Mater. Today: Proc. 2017, 4, 3972-3978.

(33) Hinman, J. G.; Eller, J. R.; Lin, W.; Li, J.; Li, J.; Murphy, C. J. J. Am. Chem. Soc. 2017, 139, 9851-9854.

(34) Yang, M.; Li, J.; Chen, P. R. Chem. Soc. Rev. 2014, 43, 6511-6526.

(35) Yu, L.; Huang, Z.; Liu, Y.; Zhou, M. J. Organomet. Chem. 2012, 718, 14-21.

(36) Li, X.; Zheng, Z.; Han, M.; Chen, Z.; Zou, G. J. Phys. Chem. B 2007, 111, 
$4342-4348$.

(37) Bouriazos, A.; Sotiriou, S.; Stathis, P.; Papadogianakis, G. Appl. Catal., B 2014, $150-151,345-353$.

(38) Ning, X.; Li, W.; Meng, Y.; Qin, D.; Chen, J.; Mao, X.; Xue, Z.; Shan, D.; Devaramani, S.; Lu, X. Small 2018, 14, e1703989.

(39) Tu, W.; Lei, J.; Wang, P.; Ju, H. Chem. Eur. J 2011, 17, 9440-9447.

(40) Ocakoglu, K.; Harputlu, E.; Guloglu, P.; Erten-Ela, S. Synth. Met. 2012, 162, 2125-2133.

(41) Zhang, Z.; Xie, J.; Yu, J.; Lu, Z.; Liu, Y. J. Mater. Chem. B 2017, 5, 1454-1460. 


\section{Figure Captions:}

Figure 1 (A) ECL responses of different TCPP-Zn-BPS nanostructures synthesized in $\mathrm{DMF} / \mathrm{H}_{2} \mathrm{O}$ with various volumetric ratios. ECL-potential curves of $\mathrm{Zn}-\mathrm{TCPP}$ (a) and TCPP-Zn-BPS (b) synthesized in (B) DMF/ $\mathrm{H}_{2} \mathrm{O}(V / V, 2: 1)$ and in (C) $\mathrm{DMF} / \mathrm{H}_{2} \mathrm{O}(V / V$, 1:1), respectively. (D) ECL behaviors of TCPP-Zn-BPS synthesized in DMF/ $\mathrm{H}_{2} \mathrm{O}$ $(V / V, 1: 1)$ with $0.05 \mathrm{M} \mathrm{H}_{2} \mathrm{O}_{2}$ during a continuous potential scan between -1.7 and 0.0 V. All the ECL behaviors were investigated in $0.1 \mathrm{M}$ HEPES containing $0.3 \mathrm{M} \mathrm{KCl}$ with $0.05 \mathrm{M} \mathrm{H}_{2} \mathrm{O}_{2}$, scan rate: $50 \mathrm{mV} \mathrm{s}^{-1}$.

Figure 2 SEM images of (A, B) Zn-TCPP and (C, D) TCPP-Zn-BPS synthesized in (A, C) $\mathrm{DMF} / \mathrm{H}_{2} \mathrm{O}(V / V, 2: 1)$ and in $(\mathbf{B}, \mathbf{D}) \mathrm{DMF} / \mathrm{H}_{2} \mathrm{O}(V / V, 1: 1)$, respectively.

Figure 3 (A) XRD powder pattern, (B) UV-vis absorption and (C) FTIR spectra of Zn-TCPP (a) and TCPP-Zn-BPS (b).

Figure 4 PL excitation spectra and emission spectra of Zn-TCPP (a) and TCPP-Zn-BPS (b).

Figure 5 Cyclic voltammograms of (A) BPS, (B) TCPP, (C) Zn-TCPP and (D) TCPP-Zn-BPS in $0.1 \mathrm{M}$ HEPES containing $0.3 \mathrm{M} \mathrm{KCl}$ in the absence (a) and presence (b) of $0.05 \mathrm{M} \mathrm{H}_{2} \mathrm{O}_{2}$, scan rate: $50 \mathrm{mV} \mathrm{s}^{-1}$. Inset $\mathbf{B}, \mathbf{C}$ and D: Magnified corresponding range.

Figure 6 EIS for Zn-TCPP and TCPP-Zn-BPS in $0.1 \mathrm{M} \mathrm{KCl}$ solution containing 5 $\mathrm{mM}\left[\mathrm{Fe}(\mathrm{CN})_{6}\right]^{4-/ 3-}$. $\mathrm{R}_{\mathrm{s}}$ : the resistance of the electrolyte solution; $\mathrm{R}_{\mathrm{ct}}$ : the charge-transfer resistance; CPE: constant phase element. 
Figure 7 PL (black curve) and ECL emission (red curve) spectrum of (A) Zn-TCPP and (B) TCPP-Zn-BPS in 0.1 M pH 7.0 HEPES buffer solution.

Figure 8 ECL-potential curves of TCPP-Zn-BPS in the $\mathrm{N}_{2}$-saturated (a), air-saturated (b) and $\mathrm{O}_{2}$-saturated (c) $0.1 \mathrm{M} \mathrm{pH} \mathrm{7.0} \mathrm{HEPES} \mathrm{buffer} \mathrm{solution} \mathrm{in} \mathrm{the} \mathrm{(A)} \mathrm{absence} \mathrm{and}$ (B) presence of $0.05 \mathrm{M} \mathrm{H}_{2} \mathrm{O}_{2}$.

Scheme 1 Schematic illustrations for the construction of TCPP-Zn and TCPP-Zn-BPS. 
Figure 1
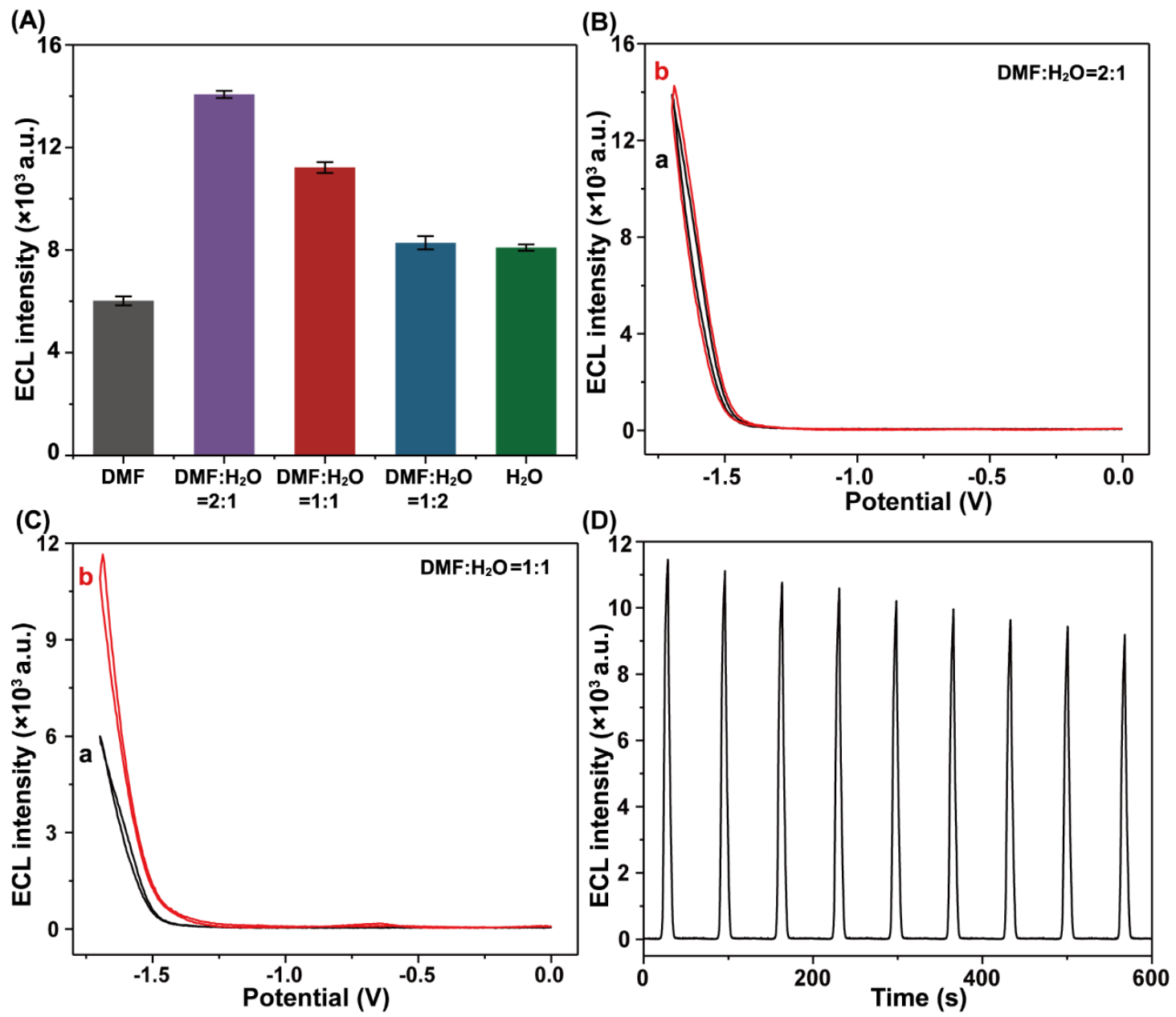
Figure 2
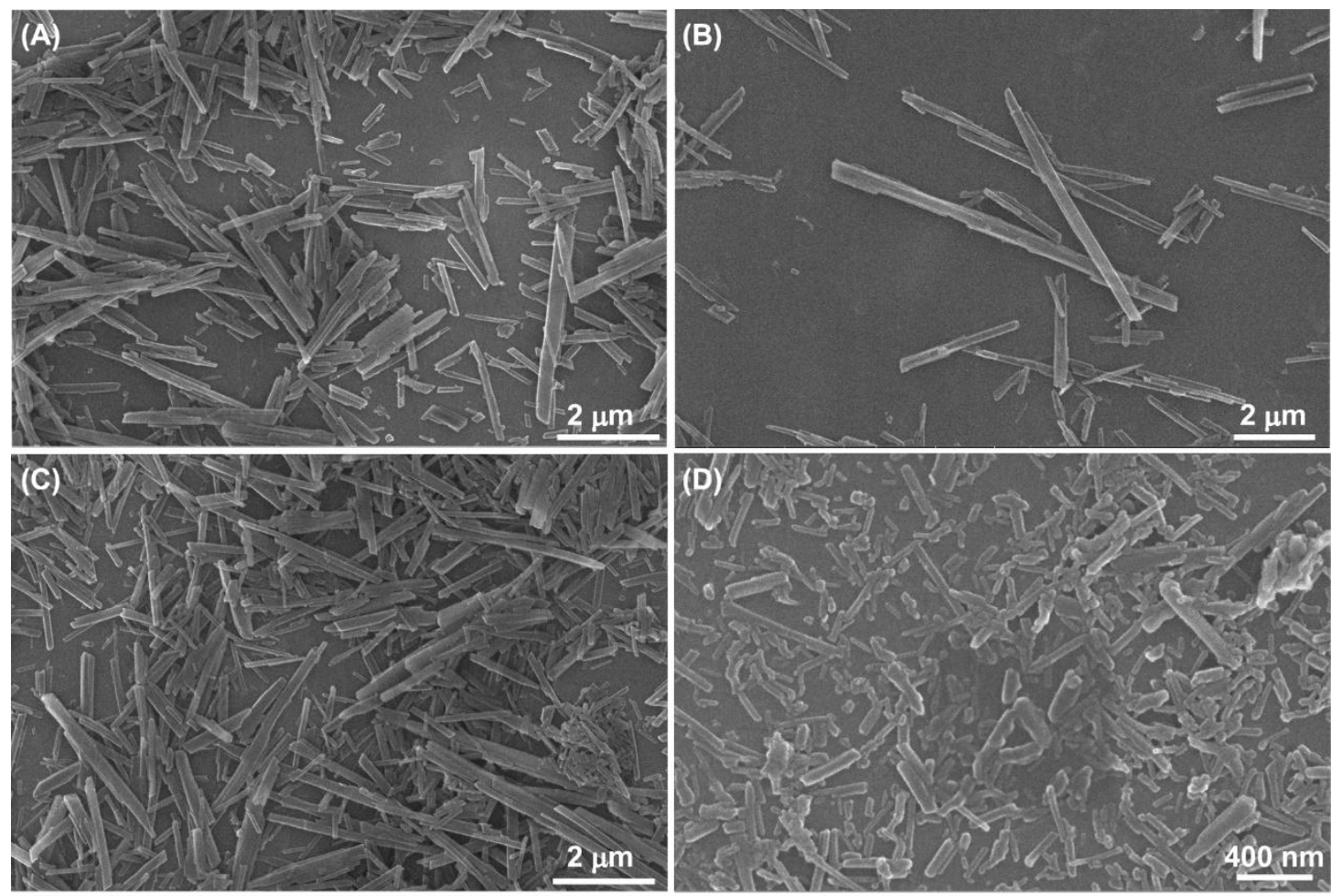
Figure 3
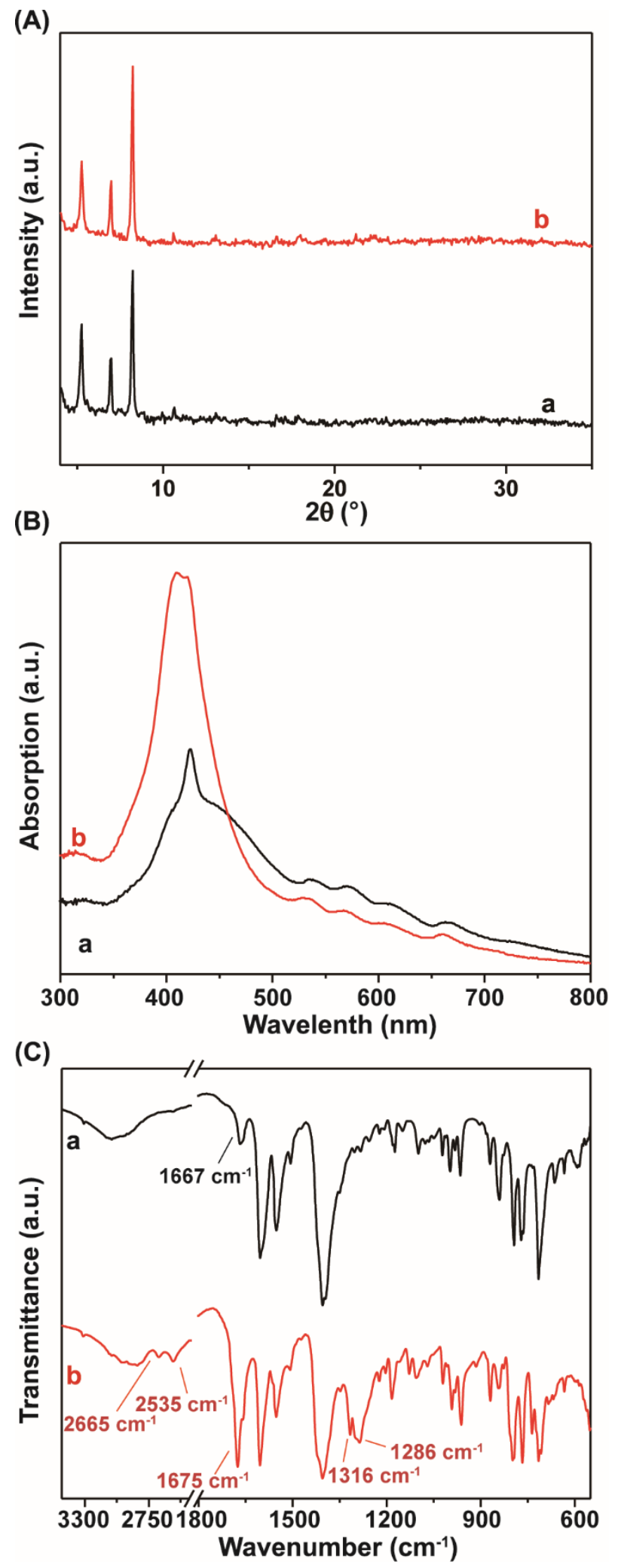
Figure 4

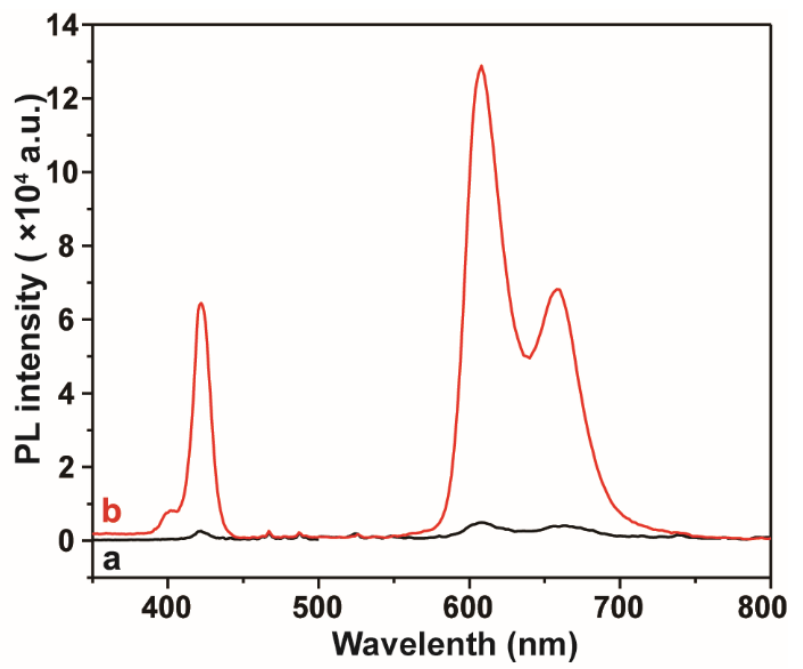


Figure 5
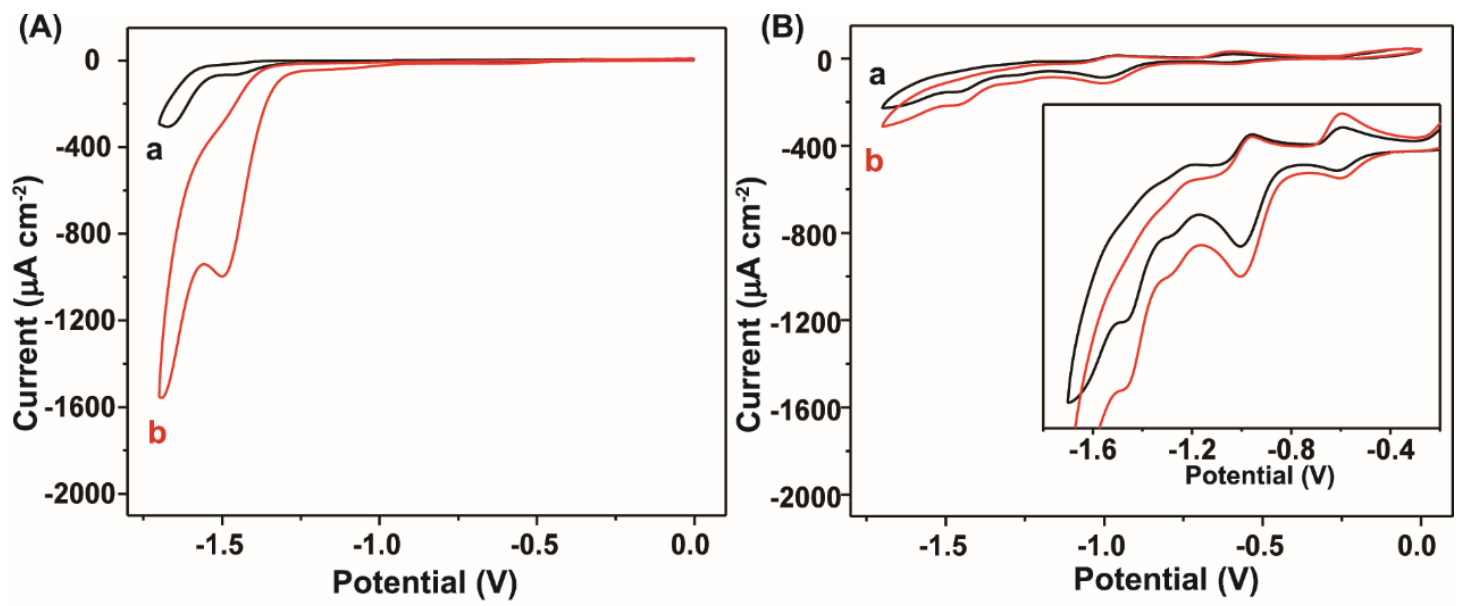

(C)

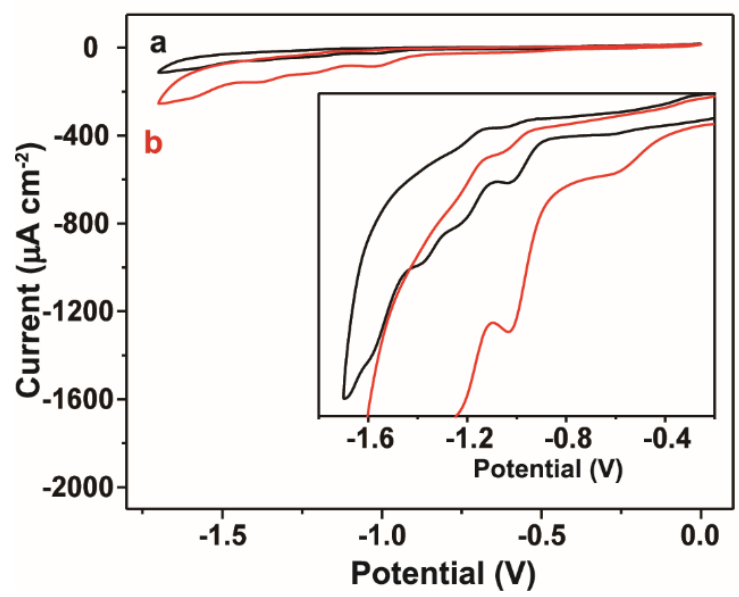

(D)

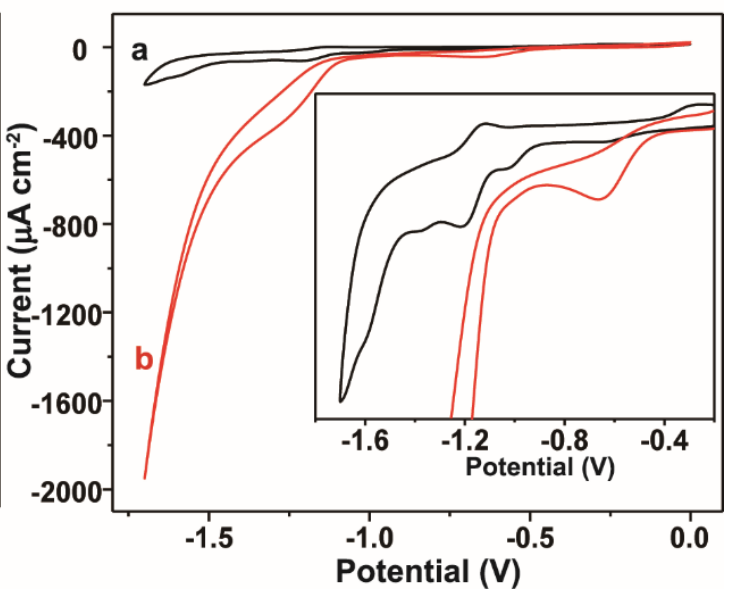


Figure 6

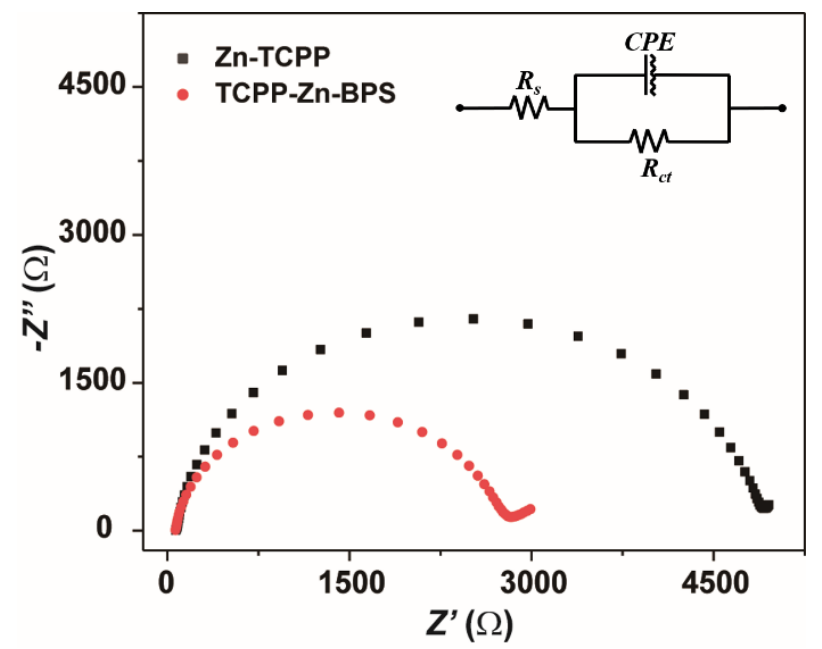


Figure 7

(A)

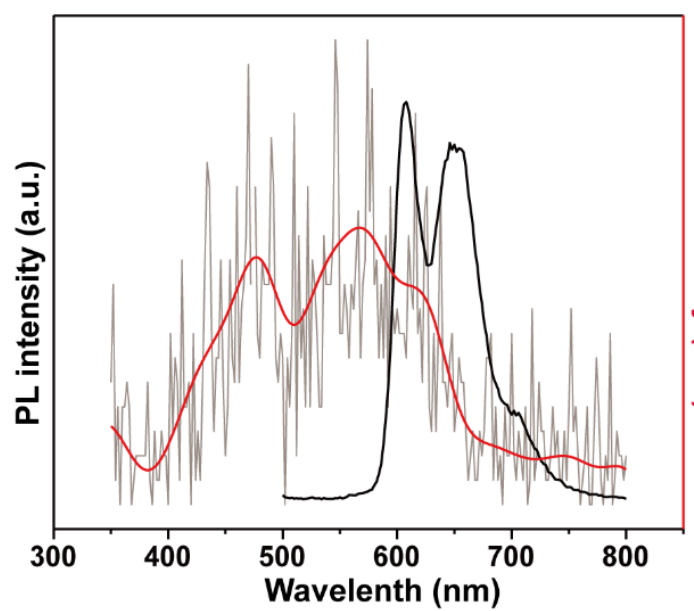

(B)

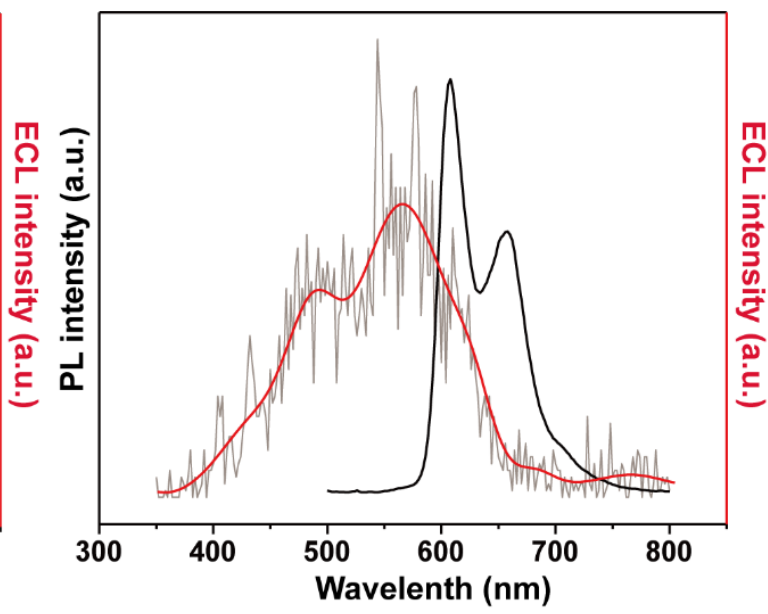


Figure 8

(A)

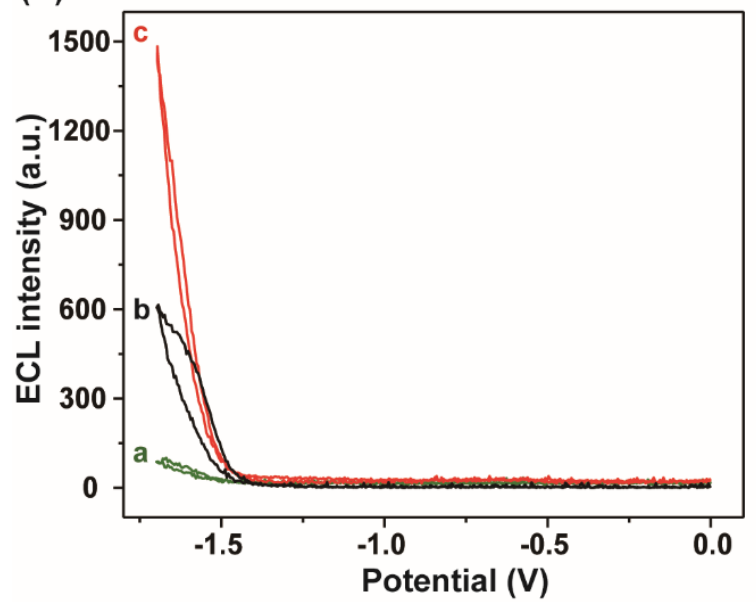

(B)

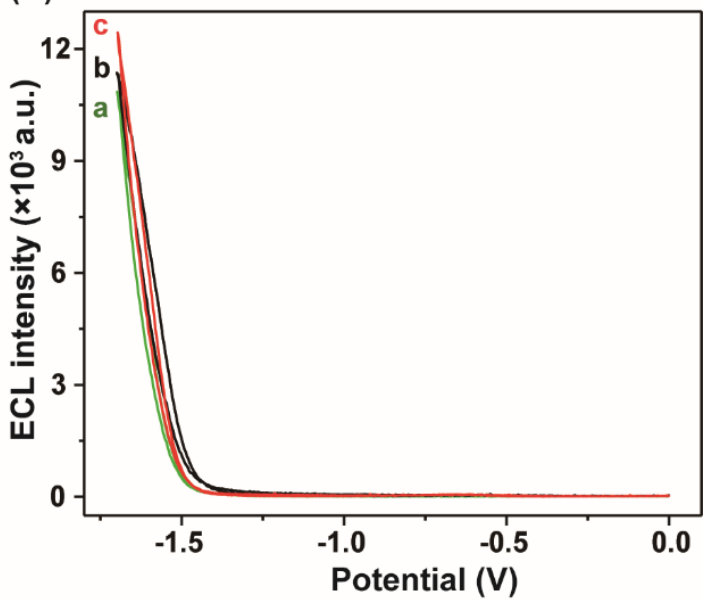




\section{Scheme 1}
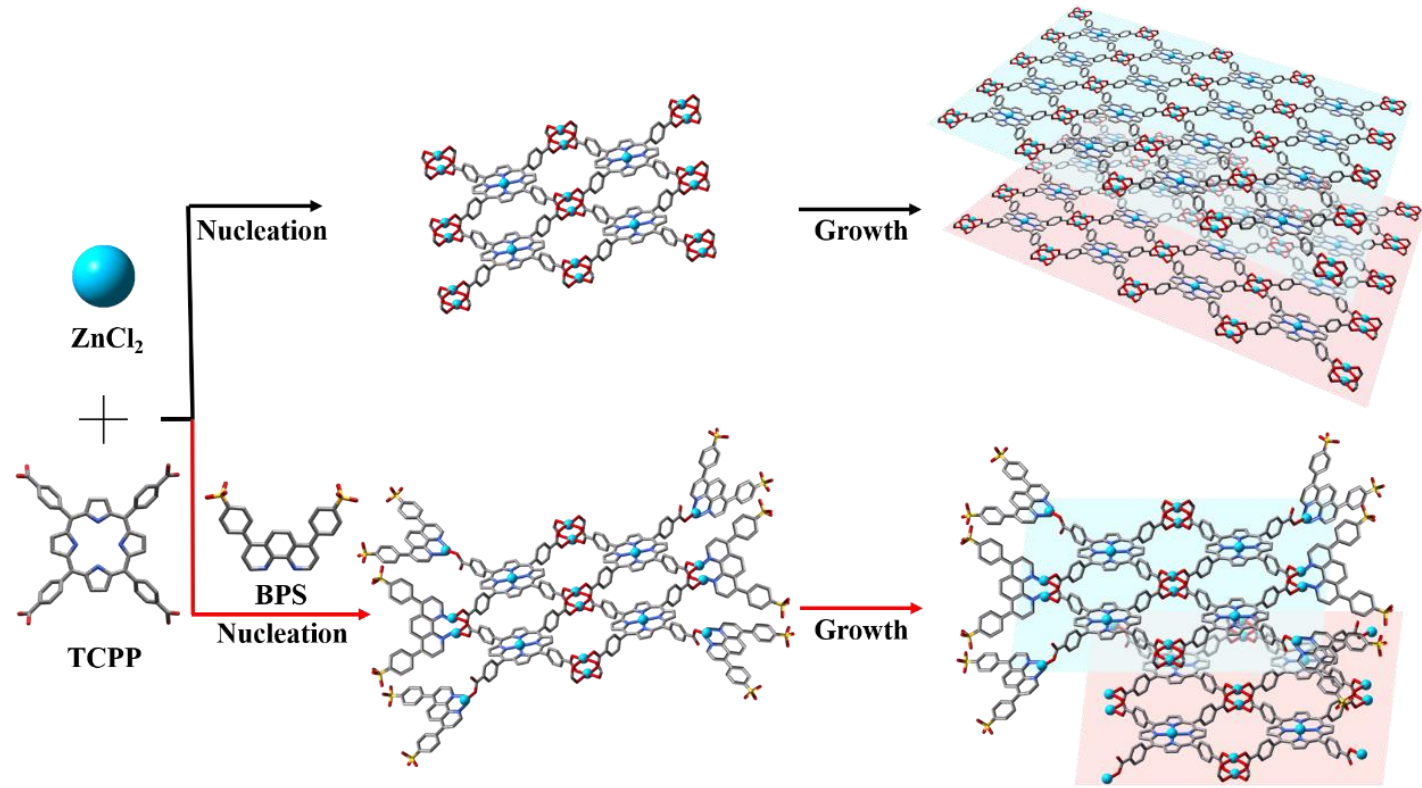
ToC

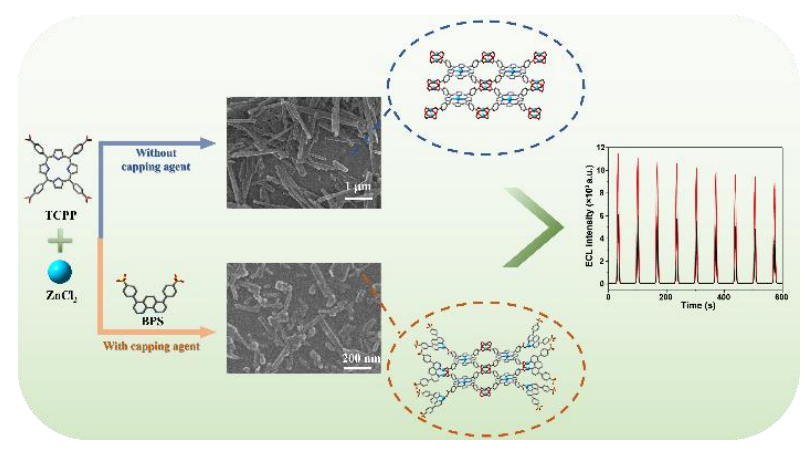

For Table of Contents Only 